\title{
Psychological Context of Overtraining Syndrome in Elite Athletes in Adolescence: Literature Review
}

\author{
Iva Burešová', Petr Květon², Martin Jelínek² \\ ${ }^{1}$ Faculty of Arts, Masaryk University \\ ${ }^{2}$ Institute of Psychology, Czech Academy of Sciences, p.r.i.
}

The study was supported by the Czech Science Foundation (Project no. 18-17783S)

\begin{abstract}
The article presents an overview of important findings concerning the overtraining syndrome (OTS) in elite athletes in adolescence. Although the scientific community agrees that OTS is a multifactorially determined and individually variable phenomenon, which can have a serious impact on the individual, there are still some inconsistencies. Therefore, in our study we focused on the terminology of the phenomenon, its prevalence, etiology and symptomatology. We paid specific attention to psychological instruments of detecting OTS indicators. Given that in the period of adolescence the training process in the majority of sport disciplines intensifies significantly, the context of developmental changes during this period in relation to OTS is discussed. The final part of the study summarizes the basic principles of prevention of this pathological phenomenon.
\end{abstract}

Key words: pathological form of fatigue, overtraining, developmental specifics of adolescence, athletes

\section{INTRODUCTION}

In the framework of elite competitive sports, the primary goal of the athletes is to maximize their performance. Usually, only those individuals who can cope with all the demands placed on them by the sport itself and by their environment can reach the performance level that allows them to compete at a national and international level (Sekot, 2014). Depending on individual dispositions and broader socio-cultural-economic conditions of an elite athlete, regular sports activity at the high performance level can play an important protective but also negative role in his or her further development and sports career (Bianco et al., 2019; Merkel, 2013). Namely, high performance sports activity is closely associated with demands, often extreme, placed on physical and mental performance of adolescent athletes. At the same time, the ever-increasing popularity of elite sports brings along an increased pressure in terms of professionalization of sports disciplines (Schubring \& Thiel, 2014). Sports load, which is associated with high performance activities of adolescents, is then also connected with high training frequency, intensity and duration. Increasing this load is a necessary pre-condition for improving sports performance, however, besides the required progress, without sufficient physical and mental regeneration it can result in increased fatigue, which can turn into its subchronic or even chronic form, in other words, the overtraining syndrome - OTS.

A whole number of significant bio-psycho-social influences are reflected to various degrees in the highly individual multifactorial reasons for the occurrence of OTS. These influences become particularly important in adolescence, when elite athletes are undergoing physical and mental maturation. The specific combination of internal and external conditions in the development of these adolescents subsequently determines whether the sports activity will potentiate the growth 
of individual areas of their development and thus play an important protective role, specifically in their physical and mental health area, or whether it will lead to a development of the pathological form of fatigue - OTS, increased injuries and eventually result in the end of the elite athlete's career (Bean et al., 2014; Difiori et al., 2014). Considering the above, early diagnosis as well as prevention of OTS play a crucial role. Both areas represent a great number of challenges for the professionals. The diagnostic procedures to detect OTS currently in use face several limitations, which will be discussed further on. Preventive steps for OTS are generally well known among professionals and laymen alike, however, they are not adequately and systematically included in the training of elite athletes. This opens up space for inappropriate load, in other words overload, placed on adolescent elite athletes, which in turn can easily lead to this pathological form of fatigue since it occurs during this key and very sensitive developmental stage. The number of serious injuries and mental issues, among other things, which are significantly on the rise in adolescence, attest to the immediate need of addressing this question (Hamlin et al., 2019; Wyatt et al., 2013).

\section{PROCEDURE}

We started the literature search in abstracts by using the terms overtraining, training distress, athlete burnout combined with sport, athlete, exercise. We used EBSCOhost (limited to APA PsychInfo, APA PsycArticles and Academic Search Ultimate databases) and Google Scholar search engines. We only included studies that were published in peer-reviewed journals, monographs and book chapters written in English, Czech or Slovak language. We build our review on sources published in the past twenty five years. Initial search on EBSCOhost returned 980 records of peer-reviewed articles and search on Google Scholar returned additional 93 articles. After initial title screening, we identified 359 unique sources which were directly related to the topic of the review. We read the abstracts of these studies and identified the key themes to be able to outline the final structure of the review. Sources highly relevant to the identified themes $(\mathrm{N}=119)$ were read in full-text and 62 of them were selected for the review as they fully cover the whole spectrum of the reviewed topic.

\section{FUNDAMENTAL TERMINOLOGY}

In professional literature, the overtraining syndrome (OTS) is usually described in the framework of individual forms of fatigue, which are associated with sports load, one of which is the chronic pathological form resulting from a reaction to prolonged high performance training load without adequate physical and mental regeneration (Carter et al., 2014). Fatigue, in sports context, is considered a complex, multifaceted phenomenon of various mechanisms of origin (e.g. type of stimuli or effort, length, frequency and intensity of the sports activity, etc.), which can be manifested by physical, mental, and physiological (local or general) fatigue. In a nutshell, in this context it can be defined as the inability of the organism to maintain the required/expected performance, whereby, the physical and mental state of the athlete as well as specific conditions of the environment play a significant role here (Halson, 2014). In view of the above, Carter, Potter, and Brooks (2014) state that common acute overload (OL) resulting from sports load, can lead to overreaching (OR), which can be in a form of functional overreaching (FOR) or non-functional overreaching (NFOR). Non-functional overreaching is considered acute pathological fatigue and can thus no longer be seen as a common or desired fatigue reaction to training load. Such 
a training maladaptation occurs mainly because of lack of balance between a sports load (e.g. excessive training demands, change in training schedule, monotony of training, and psychosocial stress) and regeneration, and it can potentially lead to chronic pathological fatigue, which tends to be associated with the occurrence and development of OTS.

Due to the fact that the subject area discussed above lacks terminological uniformity represented by the following most frequently used terms: training load syndrome, burnout syndrome, adaptive failure, syndrome of inexplicable decrease in performance, exhaustion, and others (Kreher \& Schwartz, 2012), we are basing the classification of fatigue and corresponding terminology on the joint consensus of the European College of Sports Science (ECSS) and the American College of Sports Medicine (ACSM) as expressed by Meeusen et al. (2013). Functional Overreaching - FOR is the result of the athlete's deliberate increase of the level of sports load followed by a decrease in performance without serious negative symptoms. Such an increase in load in the form of short-term functional overreaching will then lead to better performance after recovery. The time necessary for regeneration ranges from days to weeks. Non-Functional Overreaching - NFOR is the result of disregarding the ratio between sports load and sufficient regeneration, resulting in prolonged load such as decrease in performance, increased fatigue, decreased vitality, sleep disruption, psychosocial stress, disruption of hormonal functions, and others. The time necessary for regeneration ranges from weeks to months. Overtraining Syndrome - OTS is the result a combination of multifactorial causes, while sports load itself is a very important but not the only reason for OTS. An individual suffering from OTS experiences prolonged decrease in performance, mood swings, neurological, endocrine and immune system disorders, etc. The time necessary for regeneration is in the range of several months. The onset and development of OTS has such long-term impact on the athlete that it can lead to early retirement from his/her athletic career (Tod et al., 2012).

\section{PREVALENCE, ETIOLOGY AND SYMPTOMATOLOGY OF OTS}

Tod et al. (2012) posit that the range of recorded occurrence of exhaustion, overtraining or burnout among athletes is very broad, from 18 to 91 percent. Meeusen et al. (2013), however, most likely presents a more realistic OTS prevalence, i.e. from 7 to 64 percent. The author points out that an athlete, who has manifested an onset of OTS is very susceptible to not only further develop it but also to relapse. Winsley and Matos (2010) present a narrower definition of OTS occurrence, estimating it to be prevalent in adolescent athletes at about 30 to 40 percent. In case of athletes competing at the highest level the estimate of OTS occurrence is somewhat higher, some authors claim it is up to 60 percent (Kreher \& Schwartz, 2012). Be that as it may, it is necessary to look at differences in the demands placed on athletes in different sports disciplines. Research studies repeatedly recorded a more frequent OTS occurrence in girls, who specialized in a sport very early, particularly in individual sports (Matos et al., 2011; Walters et al., 2018). The discrepancy in the prevalence of OTS is caused by a number of limitations of research studies dealing with this subject, for example, the use of different research methods, the heterogeneity of the research sample, data collection at various stages of the training cycle, the competition season, etc. In spite of the fact that data in professional literature concerning OTS in adult and adolescent athletes are not completely unanimous, professionals in this field do agree that OTS presents a significant problem, which affects not only elite athletes' progress in their sports discipline but also their physical and mental health, which can play a key role in subsequent stages of their development in adolescence. 


\subsection{Risk factors contributing to the occurrence and development of OTS}

Tod, Thatcher, and Rahman (2012) identify the following risk factors contributing to the occurrence and development of OTS: biological factors (talent and disposition affecting the ability to deal with the training amount and intensity); situational factors (competition season progression, demands outside their sports activity); interpersonal factors (relationship with coaches and parents, etc.); athlete factors (fear of not being picked for a competition, ability to deal with precompetition nerves, etc.); sociocultural factors (pressure by peers, family, fans). In their research study, Carter et al. (2014, see Fig. 1) present a diagram of possible causes of OTS development, in which the dominant role is played by principles of a training program. When these principles are disrupted, in combination with other factors, the results may be a maladaptive reaction to an excessive training load. In line with this, Lehmann et al. (1998) confirm that the risk of OTS is increased by one-sided monotonous training, lack of good rest, excessive volume or training load in combination with a large number of competitions. Many authors perceive overtraining as the last of the three maladaptive phases of training. In this context, Matos et al. (2011) describe the first of these phases as a training plateau, the second as the occurrence of psychophysiological dysfunctions, and in the third phase, which some authors describe as burnout, the athlete's ability to react to stress has been exhausted. However, burnout and OTS are two different concepts, which should not be used interchangeably. The key to the differentiation between burnout and overtraining can be the motivation to continue training, where the overtrained athlete can still be motivated to continue to train while the burned out athlete is not (according to some models overtraining is the so-called prerequisite for burnout).

Figure 1. Causes of Overtraining Syndrome (adapted from Carter et al., 2014, p. 4)

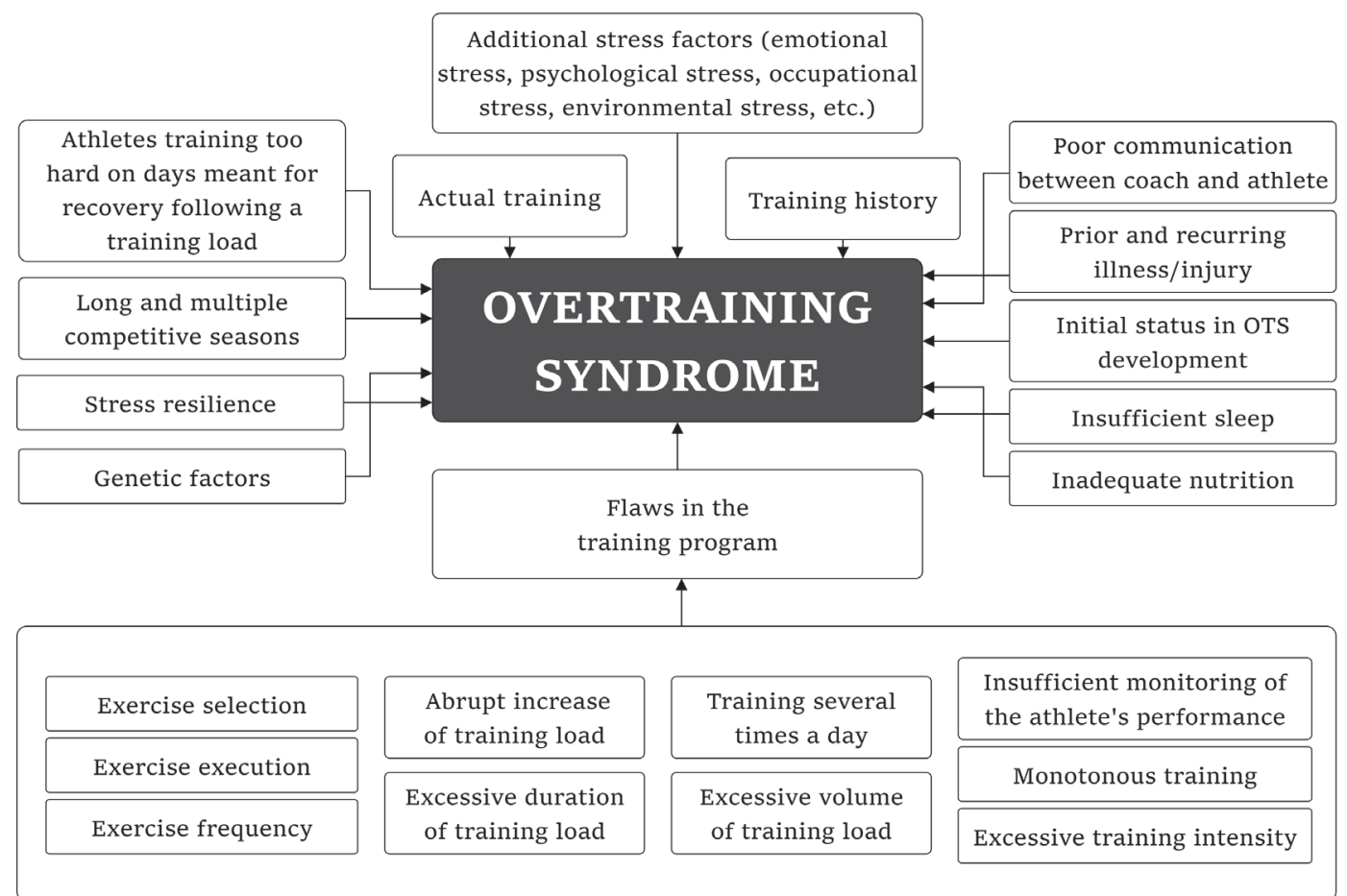


At the same time, OTS is typically accompanied by high interindividual variability of symptoms. An athlete with a beginning or fully developed OTS may experience sympathetic as well as parasympathetic changes or combinations thereof (Wallace et al., 2009). Parasympathetic changes, ascribed to OTS, occur more often in endurance sports athletes, while sympathetic changes are more common in anaerobic sports (Urhausen \& Kindermann, 2002). Moreover, the occurrence and development of OTS is associated with a number of additional symptoms (see Table 1).

Table 1. Main symptoms of OTS (adapted from Carter et al., 2014)

\begin{tabular}{lll}
\hline $\begin{array}{l}\text { Parasympathetic changes } \\
\text { (more common in }\end{array}$ & $\begin{array}{l}\text { Sympathetic changes } \\
\text { (more common in } \\
\text { aerobic sports) }\end{array}$ & Additional symptoms \\
\hline fatigue & insomnia & eating disorder \\
depression & irritability & weight loss \\
bradycardia & restlessness & muscle pain/stiffness \\
loss of motivation & tachycardia & decreased concentration \\
& hypertension & and attention ability \\
& absent-mindedness & anxiety \\
& & lethargy \\
\hline
\end{tabular}

OTS symptoms can be divided into several basic areas, in which they manifest themselves to a significant degree. Performance symptoms include, for example, decrease in specific and general performance, deficiency in agility, speed, strength and endurance, aversion to sports activity, insecurity during training or learning new elements or during a performance, fear of training sessions and competitions. Somatic symptoms include changes in reaction time, sweating, disruption in concentration, sleep and digestion, blood pressure fluctuation, consistent fatigue, and increased occurrence of illnesses. Neuropsychological symptoms involve feelings of unrest and tension, increased irritability, apathy or, vice versa, oversensitivity, inappropriate mental reactions (explosions of aggression, or lachrymosity), indecisiveness, depression, disruptions in perceiving the outside environment (heat, noise), changes in libido, etc. (Meeusen et al., 2013). The symptoms of overtraining in adolescents are identical to those of the adult population. Some other symptoms specific to adolescents are: more conflicts with the family, partner, trainer or friends; decreased interest in trainings and competitions; increased frustration during training sessions; decrease in self-confidence; difficulties with concentrating on specific tasks; irritability; depression; gloom; and increased level of stress subjectively perceived (Hollander et al., 1995). Hoffman and Kaminsky (2000) point out that OTS symptoms are often underestimated because of their highly individualized variability, and that the occurrence of OTS can be the tip of the iceberg, following repeated warnings in the form of symptoms, to which the athlete and the coach did not pay enough attention.

\subsection{OTS models}

It is quite obvious from the above that the occurrence of OTS presents not only a multifactorial but also a highly individually variable picture of the causes. Currently, there is no unequivocal agreement among the authors specializing in this area, concerning the causes of OTS and its expressions or whether OTS develops continually, exclusively from repeated or long-term nonfunctional overreaching, or whether OTS can occur as a result of some significant trigger stressor, which would seriously negatively affect either functional or non-functional overreaching. This is the reason for the development of several theoretical OTS models. The following are key multisystemic OTS models: The Multi-Systemic Model of Overtraining (Meyers \& Whelan, 1998); 
The Conceptual Model of Overtraining (Kenttä \& Hassmén, 1998); and The Overtraining Risks and Outcomes Model (Richardson et al., 2008).

The Multi-Systemic Model of Overtraining by Meyers and Whelan (1998) emphasizes the necessity of a complex understanding of the sources of load/stress affecting athletes. At the same time, it is creating a framework for understanding the reasons why athletes with similar abilities and skills undergoing almost identical sports load manifest a relatively broad range of reactions to this load, going from positive all the way to negative forms of adaptation. The authors also emphasize that their model includes, in addition to the interaction between load/stress and compensation strategies, other variables in the process of OTS development. Among these are a) variables pertaining to sports training, b) biological, cognitive, behavioral, and emotional characteristics of the athlete, including his/her sports ability and skills, and c) factors coming from a broader environment involving interaction with coaches, teammates, peers, family members, other persons close to them, and teachers, as well as the effects of cultural and economic situation. The key assumption of this model is the premise that an individual's experience in one type of environment/context will influence the experience in other contexts. The authors of the model take into account not only currently present load/stressors within various systems and contexts but also significant past events and experiences from the athlete's life to date.

Kenttä and Hassmén $(1998 ; 2002)$ presented a Conceptual Model of Overtraining, which encompasses the process of adaptation and maladaptation to load in the context of broader conditions in the athlete's life, while taking into account sports as well as non-sports factors, which can potentially lead to the development of OTS. This model defines overtraining as an interaction process, which comprises three main systems: physiological, psychological and social. In each one of them there are three dynamic components, which influence the overall equilibrium between load/stress and regeneration: stress, resilience toward stress and recovery. In this model, the central aspect of negative adaptation to sports load is physiological stress (e.g. training), illness or using medication is not taken into account. Psychological (intrapersonal) stress occurs, when, for example, there is a discrepancy between the athlete's expectations and his/her actual performance, while social stress is defined as the result of interaction with others. In the end, psychological and social stress in combination with physiological stress determine the degree of actual stress experienced by the athlete. The conceptual model of overtraining applies a holistic approach to the evaluation of the athlete's actual state and actual resilience, level of experienced stress and activities supporting the athlete's regeneration. The athlete's resilience, according to this model, determines the level of stress the individual is able to tolerate; for example, there is neuromuscular resilience (i.e. aerobic and anaerobic capacity), resilience to psychological stress (i.e. self-confidence level, anxiousness, motivation, focus, mental health and attitudes), or resilience to social stress (i.e. ability to create, cope with and maintain relationships with others). These types of resiliences together create the athlete's overall resilience to various types of stresses (Kenttä \& Hassmén, 1998).

Richardson et al. (2008) in The Overtraining Risks and Outcome Model concentrate mainly on the risk factors influencing negative adaptation to sports load and thus potentially playing an important role in the development of OTS (e.g. some training aspects, situational and environmental stressors, interpersonal aspects, the athlete's physical condition, his/her beliefs and attitudes, etc.) The concept of the model involves four hierarchically arranged levels describing the relationship between stress, recovery and overtraining in athletes. Level 1 describes risk factors, which can deepen reaction to stress, and divides them into situational, intrapersonal and interpersonal factors. Level 2 deals with the imbalance between stress and recovery, which can lead to the first warning signs of overtraining (indicating that the athlete is not able to cope with the demands of the sports load or the demands in other parts of his/her life). Lever 3 includes the 
athlete's reaction to these warning signs. These reactions are influenced by the factors described in Level 1 and together they determine whether the athlete will be able to recognize the symptoms of overtraining and choose the appropriate strategy to cope with them. Level 4 represents the consequences, where in general, the athlete can adapt and return to the original balance between stress and recovery or, if the athlete does not recognize the signals or has an inappropriate reaction, s/he can end up with a full development of OTS.

All the above discussed models are focused on the process of adaptation/maladaptation to load, which can lead to OTS. At the same time, they emphasize the necessity of a contextual approach to researching, diagnosing and preventing OTS. Furthermore, in the context of the occurrence of OTS, there is another condition, which needs to be taken into account in adolescents and that is the developmental specifics of adolescence, because this developmental stage is undoubtedly one of the key phases of development during which elite athletes experience a number of significant biological, psychological and social changes (Dennison, 2016), which can often play a fundamental role in the occurrence of OTS.

\section{DEVELOPMENTAL SPECIFICS OF ADOLESCENCE IN THE CONTEXT OF OTS DEVELOPMENT}

During adolescence elite athletes are undergoing not only a number of developmental changes, which will be discussed later, but also their sports career requires of them significant changes in the training. Nowadays, training in all sports disciplines changes from a specialized training to elite training. Peřič (2004) characterizes specialized training mainly by gradually increasing intensity of training load and crossing over to a target training stimuli, while elite training is defined primarily by high volume and intensity of training units. This type of training in adolescent athletes should be adjusted not only to the type of a given sports discipline but also to their biological age, while taking into account biological, in other words, anatomic-physiological peculiarities of the physical load placed on a developing organism as well as the appropriateness of the psychosocial demands placed on these athletes. In practice, however, elite training is often not adjusted to the corresponding developmental specifics of a given age group, despite the fact that adolescent elite athletes differ from adults in such important features as the skeletal system, heat tolerance, heart functions, thought process or self-regulation (Martinková, 2013). Neither do coaches give enough consideration to the fact that this developmental stage is characteristic for significant interindividual as well as intraindividual variability in the maturity of the adolescent, in the framework of all the areas of development discussed below. Moreover, a significant role is played by genetic and gender influences and broader sociocultural and socioeconomic conditions. Thus, each adolescent individual may react differently to the identical degree of sports load (Rearick et al., 2011), and these individual differences are manifested predominantly in the developmental areas discussed in the following sections.

\subsection{Physical Development}

Physical changes during adolescence are determined predominantly by physiological growth along with significant hormonal changes, which potentiate physical and motor development of the adolescent. During this period, there is a significant progress in the area of fine motor skills (hand-eye coordination, dexterity development), as well as gross motor skills (stability, control of core and limbs), coordination and overall physical performance and endurance (Kučera et al., 2011), growth of muscle mass, and important skeletal changes. Optimizing the intensity of sports load is, therefore, very important during this developmental stage, mainly because of the possible 
benefits of a regular sports activity, as proven by a great number of research studies. Regular sports load in adolescents is associated with, for example, the improvement in mineralization and volumization of bones, or with changes in the progress of sexual maturity (Bertelloni et al., 2006), and its positive role in maintaining optimal weight has been proven by many studies (Janssen \& LeBlanc, 2010). The level of physical development in elite athletes is simultaneously an important source of self-concept, self-esteem and self-confidence and it is reflected in the process of identity creation (see next section).

\subsection{Cognitive Development}

The maturation process of cognitive functions is reflected in important quantitative and qualitative changes in the thought processes, be it a metacognitive development, thinking flexibility, abstract, hypothetical-deductive thinking or the development of memory and imagination, all of which are reflected primarily in the precision of the sports performance. Furthermore, the development of metacognition in elite athletes plays a key role, mainly in adopting the correct strategies, attitudes or understanding of mechanism by means of which it is possible to attain higher or better sports performances. At the same time though, the early changes in the dopaminergic systems are behind the fact that the reasoning of adolescents is set up to search for extraordinary experiences, which is reflected in their risk-taking tendency, because they are still unable to resist potentially dangerous but highly attractive impulses (Pate et al., 2000). This fact, can then be manifested in, for example, underestimating the current or long-term sports load and so contribute to OTS development.

\subsection{Emotional Development}

The emotional rollercoaster in this developmental stage is primarily the result of hormonal changes manifested in emotional egocentrism, mood change, oversensitive reactions, feelings of frustration, expressions of instability, irritability and emotional confusion. As early as 1996, Steptoe and Butler came to the conclusion that intensive participation of adolescents in sports is positively associated with lower emotional stress and higher level of emotional well-being, regardless of gender, or socioeconomic status. A study by Brosnahan et al.(2004) has shown the important protective effect of regular sports activity on mental health, mainly in the context of decreased occurrence of feelings of sadness, depressive symptomatology and risk of contemplating or even planning suicide, which happens to be one of the most often stated reason for untimely death during this developmental stage. However, there are negative aspects of sports activities connected with development of OTS, which bring undesirable negative changes in emotionality, such as mood swings, increased impulsivity or irritability (Sagar et al., 2009).

\subsection{Personality Development}

Within the framework of adolescence and according to broader conditions involved in the development of an individual, a highly specific process of personality individuation and development of social as well as personality aspects of identity is taking place (Schwebel et al., 2016). Herein, the social role of an elite athlete plays an undoubtedly significant role, and as previously mentioned, regular sports activity is reflected in the level of self-concept, self-esteem and selfconfidence (Stein et al., 2007). At the same time, sports activity can have a positive influence on behavioral development in terms of learning fair-play or personal responsibility (Escartí et al., 2010; Wiese-Bjornstal et al., 2009). During this developmental stage, there are also significant changes happening as far as internal and external motivation is concerned, and internal differentiation of self-regulation mechanism and coping strategies is taking place as well. The utilization of these is, to a great extent, influenced not only by regular sports activity but also by its broader 
circumstances (type of sports discipline, difficulty of the physical and mental sports training, etc.). In this context, the development of the introspection ability is very important, because, for example, by self-monitoring, an individual can identify and control his/her performance mechanisms, which is also the basic condition for preventing OTS (MacIntyre et al., 2014). As far as OTS is concerned, research has found its significant associations with some personality traits - primarily neuroticism (Sagar et al., 2009), conscientiousness (Judge \& Ilies, 2002), or maladaptive forms of perfectionism (Gucciardi et al., 2012).

\subsection{Social Development}

A number of research studies prove the positive effect of intense physical activity on social functioning of an individual (Allison et al., 2005). Undoubtedly, participating in sports has a positive effect on social development of adolescents, because it develops not only their ability to cooperate but also a broader spectrum of other social skills associated with, for example, emotional control (Eime et al., 2013). Moreover, Lansford (2016) claims that an individual who socializes is usually happier and more adaptable than socially isolated individuals. Merkel (2013) further points to the importance of social support and acceptance, which makes it possible to be part of a team in the context of prevention of risk behavior, including suicide risk. She bases her claim on the assumption that athletes who have a strong social support are more resilient to negative impacts. Elite athletes' social development in adolescence is dependent not only on the quality of family, peer and later partner relationships but also on the important role of the relationships in school and sports environment (particularly with the coach). In the context of OTS development another key role is played by parent and coach motivation climate, which affects the way elite athletes perceive, evaluate and react to situations associated with overcoming sports load and attaining goals. Numerous research results connect maladaptive behavior patterns and motivation with performance motivation climate (Weigand et al., 2001).

\subsection{Academic path development}

One of the specific areas, which in adolescence can significantly contribute to the occurrence and development of OTS, involves school work demands. Around the age of 15 the majority of adolescents is completing the so-called compulsory schooling, which generally brings a change in the environment as well as relationships. At this time, adolescent athletes, while deciding about their possible professional sports career, are confronted by the pressure to also take on the responsibility of choosing their future profession. During adolescence, this usually results in a greater conflict between the demands associated with school preparation and the demands placed on sports performance. There are many research studies addressing the issue of premature career ending of elite athletes (Latorre-Román et al., 2018), nonetheless, the number of studies dealing with premature ending of elite athletes' academic path is far lower. Professional literature seems to include rather works testifying to the positive influence of sports performance on school success. Georgakis et al. (2015) carried out an analysis of the relationships among academic results in elite athletes and their peers. Their findings indicated that in spite of demanding training and certainly demanding time schedules, elite student athletes reached the same or better school results than their peers. A study by Baron-Thiene \& Alfermann (2015), dealing with the optimization of the conditions for linking academic education of adolescent athletes attending sports schools and their sport career concluded that a significant role in maintaining the students' successful sports performance is played mainly by their personality characteristics, motivation and will. A study by Sorkkila et al. (2020) focused on examining the sources of the development of burnout syndrome in adolescent athletes in the context of school work demands. The results, as far as elite athletes are concerned, indicate that the burnout syndrome in sport is not context specific and that elite 
athletes, who are in danger of experiencing burnout in sport, are simultaneously experiencing symptoms of school burnout, which subsequently spill over to the area of sport. At the same time, some OTS models consider the burnout syndrome to be one of the most significant results of overtraining, when the athlete is no longer able to cope with the physical and psychological demands of the sport. Tod et al. (2012) define burnout syndrome as "withdrawing from the sport, physically or psychologically, characterized by a diminishing feeling of the ability to succeed, by devaluing the activity and by exhaustion".

\section{MEASURING METHODS}

Based on all the above, it is clear that identifying OTS requires a complex and multidisciplinary diagnosis in order to encompass all the key areas in which all the main symptoms are reflected. Alves et al. (2006) divided these symptoms into six categories: physiological (e.g. pulse frequency in the morning hours); psychological (e.g. mood swings, sleep disturbances, increased emotional lability, propensity to conflicts, decreased self-esteem); biochemical (e.g. low concentration of muscle glycogen, mineral deficit); immunological (e.g. higher concentration of specific as well as unspecific immunocompetent cells in the body); performance (e.g. decrease in performance, decreased ability to reach maximum performance); and cognitive indicators (e.g. decrease in concentration or decreased psychomotor tempo). The basic principle of diagnosing the pathological forms of fatigue, therefore, is to identify changes in the overall reaction of the organism and the speed of recovery following a load. According to Kreher and Schwartz (2012), overtraining diagnosis focuses on three basic areas: decrease in performance, mood swings, and absence of symptoms indicating a different explanation for the decrease in performance. If after the unexplained decrease in performance the athlete returns to previous performance level in less than 3 weeks, it is considered overreaching, however, if the return to previous performance level lasts longer, it is usually considered overtraining. Unfortunately, presently there is no diagnostic tool that would be able to unequivocally diagnose OTS and the degree of its development. This is due to the general as well as highly interindividual variability of its symptoms, which are also often characteristic of a whole number of common illnesses. To date, we are not able to differentiate between overreaching and overtraining with a satisfactory diagnostic certainty.

\subsection{Medical and non-medical methods used in OTS diagnosis}

Simply put, specific procedures used to diagnose OTS can be divided into medical and nonmedical methods. Unfortunately, the medical methods have not been able to find the so-called final biomarker, which would be able to distinguish functional overreaching from nonfunctional one and both types from OTS (Carter et al., 2014). As discussed above, OTS symptoms are relatively nonspecific and can also represent the symptoms of many other illnesses, which must first be eliminated when diagnosing OTS. That is the reason why identifying OTS must involve a very complex clinical diagnostic process, including medical history, sleep quality evaluation, looking at nutrition, injuries, and training in relation to the athlete's individual personal history. This means that in the framework of identifying OTS, a number of specific biomarkers are examined, such as oxygenation stress, hematological and immunological markers, and others, in addition to the common laboratory screening tests (blood panel, speed of erythrocytes sedimentation, C-reactive protein, iron, creatine kinase, and thyroid stimulating hormone levels) (Kreher, 2016). Moreover, checking immunoglobulin, cortisol or uric acid levels, maximal heart rate, heart variability, or lactate exchange values during performance testing are all part of the evaluation process. Very often the OTS diagnostic process also utilizes physiological and functional tests, which aid in 
proving excessive load on the body (Meeusen et al., 2006; 2013). The most promising results in terms of differentiating between overreaching and overtraining lie in the combination of using performance testing and physiological markers.

On the nonmedical level, to map OTS a combination of the following methods is used most commonly: self-assessment, retrospective or present-focused questionnaires and methods aimed at subjective evaluation of the degree of perceived psychological load, training diaries and direct observation. Performance tests can also be utilized focused on psychomotor tempo and attention concentration (e.g. Stroop test) as well as other cognitive tools (Hausswirth et al., 2013). In terms of the above, it is worth to mention that similarly to the case of biomarkers, none of the psychological methods used (see the overview of tools used in OTS diagnosis in Table 2) makes an unequivocal final diagnosis possible. These diagnostic tools are used in research and practice, mainly as indicators of the degree of psychological load in elite athletes which accompany OTS.

Table 2. The most commonly used methods to determine psychological symptoms of OTS

\begin{tabular}{lll}
\hline Method & Reference & Description \\
\hline $\begin{array}{l}\text { Daily Analysis of Life Demands } \\
\text { of Athletes (DALDA) }\end{array}$ & Rushall, 1990 & $\begin{array}{l}\text { Self-report of sources of stress in everyday } \\
\text { life (part A, 9 items) and symptoms of } \\
\text { experienced stress (part B, 25 items). }\end{array}$ \\
\hline Profile of Mood States (POMS) & $\begin{array}{l}\text { McNair, Lorr, \& Droppleman, } \\
\text { 1971 }\end{array}$ & $\begin{array}{l}\text { Self-report scale for profiling affective } \\
\text { states and moods. 65 items (short versions } \\
\text { were published too). }\end{array}$ \\
\hline $\begin{array}{lll}\text { Le Société Française de } \\
\text { Médecine du Sport (SFMS) }\end{array}$ & Legros, 1993 & $\begin{array}{l}\text { Scale determining the presence of over- } \\
\text { training symptoms in physical and emo- } \\
\text { tional area. 54 items. }\end{array}$ \\
\hline $\begin{array}{ll}\text { Training Distress Scale (TDS) } \\
\text { Raglin \& Morgan, 1994 }\end{array}$ & $\begin{array}{l}\text { Method focused on key physical (e.g. } \\
\text { muscle and joint pain, lack of energy, etc.) } \\
\text { as well as mental aspects (e.g. lack of con- } \\
\text { centration, irritability, etc.) of sports load. } \\
19 \text { items. }\end{array}$ \\
\hline $\begin{array}{l}\text { Recovery Stress Questionnaire } \\
\text { for }\end{array}$ & Kellmann \& Kallus, 2001 & $\begin{array}{l}\text { Complex method focused on expressions } \\
\text { of stress and strategies to cope with it. 76 } \\
\text { items. }\end{array}$ \\
\hline $\begin{array}{l}\text { Short Overtraining Symptoms } \\
\text { Questionnaire (SOSQ) }\end{array}$ & $\begin{array}{l}\text { Lemyre, Roberts, \& Stray- } \\
\text { Gundersen, 2007 }\end{array}$ & $\begin{array}{l}\text { Brief questionnaire designed to determine } \\
\text { symptoms of overtraining. 5 items. }\end{array}$ \\
\hline
\end{tabular}

Despite high individual variability of symptoms intertwined with different degrees of intensity in the diagnostic panel of OTS, some symptoms compared to others occur more frequently, for example, mood swings, depression, sleep and eating disturbances, lowered immunity, concentration difficulties and others (Lastella et al., 2018). Given what has been said, psychological tools with good psychometric parameters appear to be very suitable in terms of quick accessibility of information about the development of the symptoms of OTS, which are relatively easy to track at low cost over time. Currently though, even in this area there is a lack of sufficient relevant conclusions which would offer adequate basis for diagnostically differentiating between functional and non-functional overreaching and between both of those and the overtraining syndrome. 


\section{PREVENTION OF THE OCCURRENCE AND DEVELOPMENT OF OTS}

Based on the discussion above, it is possible to summarize that the fundamental building block of preventing the occurrence and development of OTS in adolescence is mainly respecting the developmental specifics and individual variability of adolescent elite athlete's psychological and physical prerequisite for a performance in a specific, given sports activity as well as continuously monitoring the current level of this activity. At the same time, it is advisable to carry out monitoring throughout training and subsequent recovery, assuming that symptoms of overtraining are not underestimated by athletes and coaches alike, and neither are illnesses and injuries, and that sufficient time is allowed for necessary healing and recovery. As presented by Carter et al. (2014), another condition for a successful preventive approach to OTS is to setup and utilize individual training plans, which accommodate the athlete's disposition and actual state. These individual plans should include corresponding compensation exercises, recommendations for supplemental sports, and suitable components of active and passive regeneration. Certainly, adequate nutrition, taking suitable supplements, keeping a good drinking and sleeping regime plays an indispensable role in preventing OTS. Another important role can be played by physical therapy (massage, electrotherapy, magnetotherapy, wraps, positioning, corrective taping, etc.), and support psychological measures (stress management, pre-start stress regulation, psychohygiene, visualization, communication with the coaches, cooperation with a psychologist, or a mental coach). There is another important aspect of OTS prevention, one that is neglected in conditions of the Czech Republic, and that is a competence development of the coaches (communication ability, empathy, planning, methods and organization of training) and, in general, education of coaches and athletes concerning the negative impact of excessive training load.

\section{CONCLUSION}

The aim of the presented study was to describe the key aspects of the overtraining syndrome in elite athletes with a specific focus on the developmental stage of adolescence. Key areas of psychosocial development of an individual in relation to risk factors for OTS development were mapped. Moreover, the study presented models of the mechanism behind the occurrence of this specific pathological form of fatigue and suggested possibilities for its diagnosis and prevention. If the training of an adolescent athlete does not adjust to his/her current individual development, the athlete can experience overtraining, which increases the risk of development of negative responses to training load. Taken in the context of the volatile course of developmental changes in adolescence, if the load is unsuitable, overtraining of a particular individual can occur more readily than during later stages of development. A timely recognition of the symptoms of OTS, its complex diagnosis and subsequent optimal selection of adequate combination of strategies supporting complete recovery and regeneration of the organism of the athlete is important not only for preventing negative impact of overtraining on current physical and mental health of adolescent elite athletes but also for averting the negative effects of OTS persisting into subsequent developmental stages and keeping the adolescents participating in the sport while moving up to the adult competition categories. 
STUDIA SPORTIVA $2021 / 1$

\section{References}

Allison, K. R., Adlaf, E. M., Irving, H. M., Hatch, J. L., Smith, T. F., Dwyer, J. J. M., \& Goodman, J. (2005). Relationship of vigorous physical activity to psychologic distress among adolescents. Journal of Adolescent Health, 37(2), 164-166. https://doi. org/10.1016/j.jadohealth.2004.08.017

Alves, R. N., Costa, L. O. P., \& Samulski, D. M. (2006). Monitoring and prevention of overtraining in athletes. Revista Brasileira de Medicina Do Esporte, 12(5), 1-5. https://doi.org/10.1590/s1517-86922006000500013

Baron-Thiene, A., Alfermann, D. (2015). Personal characteristics as predictors for dual career dropout versus continuation A prospective study of adolescent athletes from German elite sport schools. Psychology of Sport and Exercise, 21(11), 42-49. https://daneshyari.com/article/preview/894260.pdf

Bean, C. N., Fortier, M., Post, C., \& Chima, K. (2014). Understanding how organized youth sport may be harming individual players within the family unit: A literature review. International Journal of Environmental Research and Public Health, 11(10), 10226-10268. https://doi.org/10.3390/ijerph111010226

Bertelloni, S., Ruggeri, S., \& Baroncelli, G. I. (2006). Effects of sports training in adolescence on growth, puberty and bone health. Gynecological Endocrinology, 22(11), 605-612. https://doi.org/10.1080/09513590601005730

Bianco, A., Ravalli, S., Maugeri, G., D'Agata, V., Vecchio, M., D’Amico, A. G., Pavone, V., Lucenti, L., Amato, A., Gentile, A., Giustino, V., Feka, K., Thomas, E., \& Musumeci, G. (2019). The "Journal of Functional Morphology and Kinesiology" journal club series: Highlights on recent papers in overtraining and exercise addiction. Journal of Functional Morphology and Kinesiology, 4(68), 1-11. https://doi.org/10.3390/jfmk4040068

Brosnahan, J., Steffen, L. M., Lytle, L., Patterson, J., \& Boostrom, A. (2004). The relation between physical activity and mental health among Hispanic and non-Hispanic white adolescents. Archives of Pediatrics and Adolescent Medicine, 158(8), 818-823. https://doi.org/10.1001/archpedi.158.8.818

Carter, J., Potter, A., \& Brooks, K. (2014). Overtraining Syndrome: Causes, consequences, and methods for prevention. Journal of Sport and Human Performance, 2(1), 1-14. https://doi.org/10.12922/jshp.0031.2014

Difiori, J. P., Benjamin, H. J., Brenner, J. S., Gregory, A., Jayanthi, N., Landry, G. L., \& Luke, A. (2014). Overuse injuries and burnout in youth sports: A position statement from the American Medical Society for Sports Medicine. British Journal of Sports Medicine, 48(4), 287-288. https://doi.org/10.1136/bjsports-2013-093299

Eime, R. M., Young, J. A., Harvey, J. T., Charity, M. J., \& Payne, W. R. (2013). A systematic review of the psychological and social benefits of participation in sport for children and adolescents: Informing development of a conceptual model of health through sport. International Journal of Behavioral Nutrition and Physical Activity, 10(98). https://doi.org/10.1186/14795868-10-98

Escartí, A., Gutiérrez, M., Pascual, C., \& Marín, D. (2010). Application of Hellison's Teaching Personal and Social Responsibility Model in physical education to improve self-efficacy for adolescents at risk of dropping-out of school. Spanish Journal of Psychology, 13(2), 667-676. https://doi.org/10.1017/S113874160000233X

Georgakis, S., Evans, J., R., Warwick, L. (2015). The Academic Achievement of Elite Athletes at Australian Schools. Journal of Education and Training Studies 3(1), 84-97. https://eric.ed.gov/?id=EJ1054901

Gucciardi, D. F., Mahoney, J., Jalleh, G., Donovan, R. J., \& Parkes, J. (2012). Perfectionistic profiles among elite athletes and differences in their motivational orientations. Journal of Sport \& Exercise Psychology, 34(2), 159-183.

Halson, S. L. (2014). Monitoring training load to understand fatigue in athletes. Sports Medicine, 44(2), 139-147. https:// doi.org/10.1007/s40279-014-0253-z

Hamlin, M. J., Wilkes, D., Elliot, C. A., Lizamore, C. A., \& Kathiravel, Y. (2019). Monitoring training loads and perceived stress in young elite university athletes. Frontiers in Physiology, 10, 1-34. https://doi.org/10.3389/fphys.2019.00034

Hausswirth, C., Schaal, K., Le Meur, Y., Bieuzen, F., Filliard, J. R., Volondat, M., \& Louis, J. (2013). Parasympathetic activity and blood catecholamine responses following a single partial-body cryostimulation and a whole-body cryostimulation. PLOS ONE, 8(8), e72658. https://doi.org/10.1371/journal.pone.0072658

Hoffman, J. R., \& Kaminsky, M. (2000). Use of performance testing for monitoring overtraining in elite youth basketball players. Strength and Conditioning Journal, 22, 54-62. https://doi.org/10.1519/00126548-200012000-00014

Hollander, D., Meyers, M., \& LeUnes, A. (1995). Psychological factors associated with overtraining: implications for youth sport coaches. J Sport Behav, 18, 3-15. https://www.researchgate.net/publication/285680246_Psychological_factors_associated_with_overtraining_Implications_for_youth_sport_coaches

Janssen, I., \& LeBlanc, A. G. (2010). Systematic review of the health benefits of physical activity and fitness in schoolaged children and youth. International Journal of Behavioral Nutrition and Physical Activity, 7(40). https://doi. org/10.1186/1479-5868-7-40

Judge, T. A., \& Ilies, R. (2002). Relationship of personality to performance motivation: A meta-analytic review. Journal of Applied Psychology, 87(4), 797-807. https://doi.org/10.1037/0021-9010.87.4.797

Kellmann, Michael, \& Kallus, K. W. (2001). The Recovery-Stress Questionnaires: User Manual. Human Kinetics.

Kenttä, G., \& Hassmén, P. (1998). Overtraining and recovery: A conceptual model. Sports Medicine, 26, 1-16. https://doi. org/10.2165/00007256-199826010-00001

Kenttä, G., \& Hassmén, P. (2002). Underrecovery and overtraining: A conceptual model. In M Kellmann (Ed.), Enhancing recovery: Preventing underperformance in athletes (pp. 57-80). Human Kinetics.

Kreher, J. B. (2016). Diagnosis and prevention of overtraining syndrome: an opinion on education strategies. Open Access Journal of Sports Medicine, 7, 115-122. https://doi.org/10.2147/oajsm.s91657 
Kreher, J. B., \& Schwartz, J. B. (2012). Overtraining syndrome: A practical guide. Sports Health, 4(2), 128-138. https://doi. org/10.1177/1941738111434406

Kučera, M., Kolář, P., \& Dylevský, I. (2011). Dítě, sport a zdraví. Galén.

Lansford, J. E. (2016). Adolescent development. In R. Biswas-Diener \& E. Diener (Eds.), Noba textbook series: Psychology (pp. 404-415). DEF publishers.

Lastella, M., Vincent, G. E., Duffield, R., Roach, G. D., Halson, S. L., Heales, L. J., \& Sargent, C. (2018). Can sleep be used as an indicator of overreaching and overtraining in athletes? Frontiers in Physiology, 9, 436. https://doi.org/10.3389/ fphys.2018.00436

Latorre-Román, P. Á., Pinillos, F. G., \& Robles, J. L. (2018). Early sport dropout: High performance in early years in young athletes is not related with later success. Retos, 33(1), 210-2012. https://recyt.fecyt.es/index.php/retos/article/view/58225

Legros, P. (1993). Le surentraînement: Diagnostic des manifestations psychocomportementales précoces. Science and Sports, 8(2), 71-74. https://doi.org/10.1016/S0765-1597(05)80048-6

Lehmann, M., Foster, C., Dickhuth, H. H., \& Gastmann, U. (1998). Autonomic imbalance hypothesis and overtraining syndrome. Medicine and Science in Sports and Exercise, 30(7), 1140-1145. https://doi.org/10.1097/00005768-19980700000019

Lemyre, P. N., Roberts, G. C., \& Stray-Gundersen, J. (2007). Motivation, overtraining, and burnout: Can self-determined motivation predict overtraining and burnout in elite athletes? European Journal of Sport Science, 7(2), 115-126. https:// doi.org/10.1080/17461390701302607

MacIntyre, T. E., Igou, E. R., Campbell, M. J., Moran, A. P., \& Matthews, J. (2014). Metacognition and action: A new pathway to understanding social and cognitive aspects of expertise in sport. Frontiers in Psychology, 5, 1155. https://doi. org/10.3389/fpsyg.2014.01155

Martinková, J. (2013). Sportovní úrazy a přetižení pohybového aparátu sportem. Mladá fronta.

Matos, N. F., Winsley, R. J., \& Williams, C. A. (2011). Prevalence of nonfunctional overreaching/overtraining in young english athletes. Medicine and Science in Sports and Exercise, 43(7), 1287-1294. https://doi.org/10.1249/MSS.0b013e318207f87b

McNair, D. M., Lorr, M., \& Droppleman, L. F. (1971). Manual for Profile of Mood States. Educational and Industrial Testing Service.

Meeusen, R., Duclos, M., Foster, C., Fry, A., Gleeson, M., Nieman, D., Raglin, J., Rietjens, G., Steinacker, J., \& Urhausen, A. (2013). Prevention, diagnosis, and treatment of the overtraining syndrome: Joint consensus statement of the European College of Sport Science and the American College of Sports Medicine. Medicine and Science in Sports and Exercise, 45(1), 186-205. https://doi.org/10.1249/MSS.0b013e318279a10a

Meeusen, R., Duclos, M., Gleeson, M., Rietjens, G., Steinacker, J., \& Urhausen, A. (2006). Prevention, diagnosis and treatment of the Overtraining Syndrome - ECSS Position Statement "Task Force." European Journal of Sport Science, 6(1), 1-14. https://doi.org/10.1080/17461390600617717

Merkel, D. (2013). Youth sport: Positive and negative impact on young athletes. Open Access Journal of Sports Medicine, 4, 151-160. https://doi.org/10.2147/oajsm.s33556

Meyers, A. W., \& Whelan, J. P. (1998). A systemic model for understanding psychological influences in overtraining. In R. B. Kreider, A. C. Fry, \& M. L. O'Toole (Eds.), Overtraining in sport (pp. 335-372). Human Kinetics.

Pate, R. R., Trost, S. G., Levin, S., \& Dowda, M. (2000). Sports participation and health-related behaviors among US youth. Archives of Pediatrics and Adolescent Medicine, 154(9), 904-911. https://doi.org/10.1001/archpedi.154.9.904

Peřič, T. (2004). Sportovní príprava dětí. Grada.

Raglin, J. S., \& Morgan, W. P. (1994). Development of a scale for use in monitoring training-induced distress in athletes. International Journal of Sports Medicine, 15(2), 84-88. https://doi.org/10.1055/s-2007-1021025

Rearick, M., Creasy, J., \& Buriak, J. (2011). Avoid Overtraining in Young Athletes. Journal of Physical Education, Recreation \& Dance, 82(5), 25-36. https://doi.org/10.1080/07303084.2011.10598624

Richardson, S. O., Andersen, M. B., \& Morris, T. (2008). Overtraining athletes: Personal journeys in sport. Human Kinetics.

Rushall, B. S. (1990). A tool for measuring stress tolerance in elite athletes. Journal of Applied Sport Psychology, 2(1), 51-66. https://doi.org/10.1080/10413209008406420

Sagar, S. S., Lavallee, D., \& Spray, C. M. (2009). Coping with the effects of fear of failure: A preliminary investigation of young elite athletes. Journal of Clinical Sport Psychology, 3(1), 73-98. https://doi.org/10.1123/jcsp.3.1.73

Sekot, S. (2014). Sociologie sportu: aktuální problémy. Brno: Masarykova univerzita. https://www.fsps.muni.cz/impact/ knihovna/sociologie-sportu-aktualni-problemy/

Schubring, A., \& Thiel, A. (2014). Coping with growth in adolescent elite sport. Sociology of Sport Journal, 31(3), $304-326$. https://doi.org/10.1123/ssj.2013-0071

Schwebel, F. J., Smith, R. E., \& Smoll, F. L. (2016). Measurement of perceived parental success standards in sport and relations with athletes' self-esteem, performance anxiety, and achievement goal orientation: Comparing parental and coach influences. Child Development Research, 2016, 1-13. https://doi.org/10.1155/2016/7056075

Sorkkila, M., Ryba, T. V., Selänne, H., \& Aunola, K. (2020). Development of School and Sport Burnout in Adolescent StudentAthletes: A Longitudinal Mixed-Methods Study. Journal of Research on Adolescence 30(S1), 115-133. https://converis. jyu.fi/converis/portal/detail/Publication/28259539

Stein, C., Fisher, L., Berkey, C., \& Colditz, G. (2007). Adolescent physical activity and perceived competence: Does change in activity level impact self-perception? Journal of Adolescent Health, 40(5), 462.e1-462.e8. https://doi.org/10.1016/j. jadohealth.2006.11.147 
STUDIA SPORTIVA $2021 / 1$

Steptoe, A., \& Butler, N. (1996). Sports participation and emotional wellbeing in adolescents. Lancet, 347(9018), $1789-1792$. https://doi.org/10.1016/S0140-6736(96)91616-5

Tod, D., Thatcher, J., \& Rahman, R. (2012). Psychologie sportu. Grada.

Urhausen, A., \& Kindermann, W. (2002). Diagnosis of overtraining: What tools do we have? Sports Medicine, 32, $95-102$. https://doi.org/10.2165/00007256-200232020-00002

Wallace, L. K., Slattery, K. M., \& Coutts, A. J. (2009). The ecological validity and application of the session-RPE method for quantifying training loads in swimming. Journal of Strength and Conditioning Research, 23, 33-38. https://doi. org/10.1519/JSC.0b013e3181874512

Walters, B. K., Read, C. R., \& Estes, A. R. (2018). The effects of resistance training, overtraining, and early specialization on youth athlete injury and Development. Journal of Sports Medicine and Physical Fitness, 58(9), 1339-1348. https://doi. org/10.23736/S0022-4707.17.07409-6

Weinberg, R. S., \& Gould, D. (2015). Foundations of sport and exercise psychology (6th ed). Champaign, IL: Human Kinetics. https://www.worldcat.org/title/foundations-of-sport-and-exercise-psychology/oclc/902708896

Weigand, D. A., Carr, S., Petherick, C., \& Taylor, A. (2001). Motivational climate in sport and physical education: The role of significant others. European Journal of Sport Science, 1(4), 1-13. https://doi.org/10.1080/17461390100071402

Wiese-Bjornstal, D. M., LaVoi, N. M., \& Omli, J. (2009). Child and adolescent development and sport participation. In B. W. Brewer (Ed.), Sport psychology (pp. 97-112). John Wiley \& Sons.

Winsley, R., \& Matos, N. (2010). Overtraining and elite young athletes. In N. Armstrong \& A. M. McManus (Eds.), The elite young athlete (pp. 97-112). Karger.

Wyatt, F. B., Donaldson, A., \& Brown, E. (2013). The overtraining syndrome: A meta-analytic review. Journal of Exercise Physiology Online, 16(2), 12-23.

\section{Contact Information}

e-mail: buresova@phil.muni.cz 